\title{
Characterizing biobank organizations in the U.S.: results from a national survey
}

\author{
Gail E Henderson ${ }^{1 *}$, R Jean Cadigan ${ }^{1}$, Teresa P Edwards ${ }^{2}$, Ian Conlon ${ }^{3}$, Anders G Nelson ${ }^{1}$, James P Evans ${ }^{4}$, \\ Arlene M Davis ${ }^{1}$, Catherine Zimmer ${ }^{2,3}$ and Bryan J Weiner ${ }^{5}$
}

\begin{abstract}
Background: Effective translational biomedical research hinges on the operation of 'biobanks,' repositories that assemble, store, and manage collections of human specimens and related data. Some are established intentionally to address particular research needs; many, however, have arisen opportunistically, in a variety of settings and with a variety of expectations regarding their functions and longevity. Despite their rising prominence, little is known about how biobanks are organized and function beyond simple classification systems (government, academia, industry).

Methods: In 2012, we conducted the first national survey of biobanks in the U.S., collecting information on their origins, specimen collections, organizational structures, and market contexts and sustainability. From a list of 636 biobanks assembled through a multi-faceted search strategy, representatives from 456 U.S. biobanks were successfully recruited for a 30-minute online survey (72\% response rate). Both closed and open-ended responses were analyzed using descriptive statistics.
\end{abstract}

Results: While nearly two-thirds of biobanks were established within the last decade, 17\% have been in existence for over 20 years. Fifty-three percent listed research on a particular disease as the most important reason for establishment; 29\% listed research generally. Other reasons included response to a grant or gift, and intent to centralize, integrate, or harmonize existing research structures. Biobank collections are extraordinarily diverse in number and types of specimens and in sources (often multiple) from which they are obtained, including from individuals, clinics or hospitals, public health programs, and research studies. Forty-four percent of biobanks store pediatric specimens, and 36\% include postmortem specimens. Most biobanks are affiliated in one or multiple ways with other entities: $88 \%$ are part of at least one or more larger organizations (67\% of these are academic, $23 \%$ hospitals, $13 \%$ research institutes). The majority of biobanks seem to fill a particular 'niche' within a larger organization or research area; a minority are concerned about competition for services, although many are worried about underutilization of specimens and long-term funding.

Conclusions: Effective utilization of biobank collections and effective policies to govern their use will require understanding of the immense diversity found in organizational features, including the very different history and primary goals that many biobanks have.

Keywords: Biobank, biorepository, governance, survey

\section{Background}

Biobanks are repositories that assemble, store, and manage collections of human specimens and related data. Although they have existed in some form for over 60 years, their recent surge in numbers, size, and prominence [1] has

\footnotetext{
* Correspondence: gail_henderson@med.unc.edu

'Department of Social Medicine, CB 7240, University of North Carolina at Chapel Hill, Chapel Hill, NC 27599-7240, USA

Full list of author information is available at the end of the article
}

focused attention on the changing nature of biomedical research and relationships among investigators, research participants, and the organizations that fund and manage these entities [2-9]. This surge in numbers coincides with success in sequencing the human genome in 2003, the subsequent explosion of new bioinformatics technologies and developments in next-generation sequencing $[10,11]$, and the vision of improved health through genomic medicine

\section{() Biomed Central}


[12]. In short, effective translational biomedical research discoveries depend upon the operation of biobanks.

Despite this reliance, we know little about biobanks. The first attempt to catalog human tissue sources in the U.S. was undertaken by the RAND Corporation [13], coinciding with the first National Bioethics Advisory Commission report on ethical and policy issues involving human biological materials [14]. Through its Handbook and the 12 case studies conducted four years later [15], RAND provided information on specimen existence, location, and access, noting that not all forms of repositories were captured. The legacy of the RAND work is the classification of biobanks into three categories (government, academia, industry) that persists in the literature [15]. Notwithstanding recent interest in classifying biobanks $[5,16]$, there is little empirical research on the organization and functioning of biobanks that might inform a more nuanced, updated classification system.

There are several reasons for this dearth in empirical research. Significant variation in biobank types leaves scholars unable to agree upon a definition [5,17-25]. In addition, no census or registry of biobanks exists from which to draw representative samples for study. Thus, while many authors have observed the importance of organizational context for understanding biobank policies, it is understudied empirically $[5,8,9,19,26-28]$. In fact, most empirical studies relevant to policy issues (for example, informed consent, identifiability, return of research results) have focused not on biobanks, but on the views of external stakeholders [29-38].

To address this gap in knowledge, we sought to describe U.S. biobanks in terms of their origins, specimen collections, organizational features, and market contexts. We applied a systematic, multi-faceted strategy to develop a list of biobanks in the U.S., and fielded a survey. Our findings document extraordinary diversity, and present baseline data upon which future analyses of organizational change, policy, and regulatory frameworks may rest.

\section{Methods}

The U.S. Biobank Survey is part of a larger study of biobanks in the U.S., funded from 2010 to 2012 by grants from the National Human Genome Research Institute and a supplement to the University of North Carolina (UNC) Clinical and Translational Science Award (CTSA). The objectives were to examine the diversity of biobanks' organizational characteristics, policies, and practices. For the purposes of our study, a biobank was defined as 'an organization that acquires and stores human specimens and associated data for future research use.' Our work included conducting six qualitative case studies, constructing a list of biobanks in the U.S. [39], and piloting and administering a 30-minute online survey. We collected data from U.S. biobank representatives on how their biobanks operate, components of organizational features identified in the literature, and the policies and practices biobanks have in place that govern their relationships with the individuals who contribute specimens and researchers who use them. This study was approved by the UNC Institutional Review Board.

\section{Construction of the list of U.S. biobanks}

Because there is no generally agreed upon definition of a biobank and no reliable census of these heterogeneous entities in the U.S., it is not possible to draw a representative sample for a national survey. In an attempt to create a comprehensive list of U.S. organizations fitting our definition of a biobank, we cast a wide net [39]. We employed multiple search strategies, similar to those used by RAND [13]. We searched articles listed in PubMed for the year 2010 and current federally awarded grant abstracts from National Institutes of Health (NIH)'s RePORTER database; and performed a systematic Google search consisting of two parts - an initial search that found individual biobanks and a follow-up search of lists and directories of biobanks that appeared in the initial search. In addition, because a significant portion of medical research is sponsored by medical institutions and research institutes, and more recently by NIH-sponsored CTSAs, we conducted searches on American Association of Medical Colleges member websites and on CTSA websites. Lastly, similar to RAND, we communicated with other investigators involved in biobank research to provide additional names, and in one case, obtained a list of biobanks [28].

We used a wide variety of keywords in our multifaceted online searches, constructing nested Boolean strings to account for the fact that some terms imply the storage of specimens (for example, 'biorepository') while other terms do not (for example, 'collection') [39]. Biobanks that did not aim to share specimens were excluded, as were biobanks without some focus on domestic research. If available information was ambiguous, we contacted the organization for clarification.

We carefully recorded and cross-referenced all sources so that we could both detect duplicates and identify the strengths and weaknesses of different sources. Of necessity, we restricted our focus to organizations for which we could find at least minimal presence on the web. That presence ranged from active marketing of the collection, to being named as entities in academic institutions or independent organizations where investigators store research specimens, to being described in an organizational newsletter.

Figure 1 depicts the number of biobank names initially identified, and the process by which we ultimately 


\section{Biobank "Hits" in a Multi-faceted Search - 1741}

\section{Biobank Names after Duplicate Hits Removed - 894}

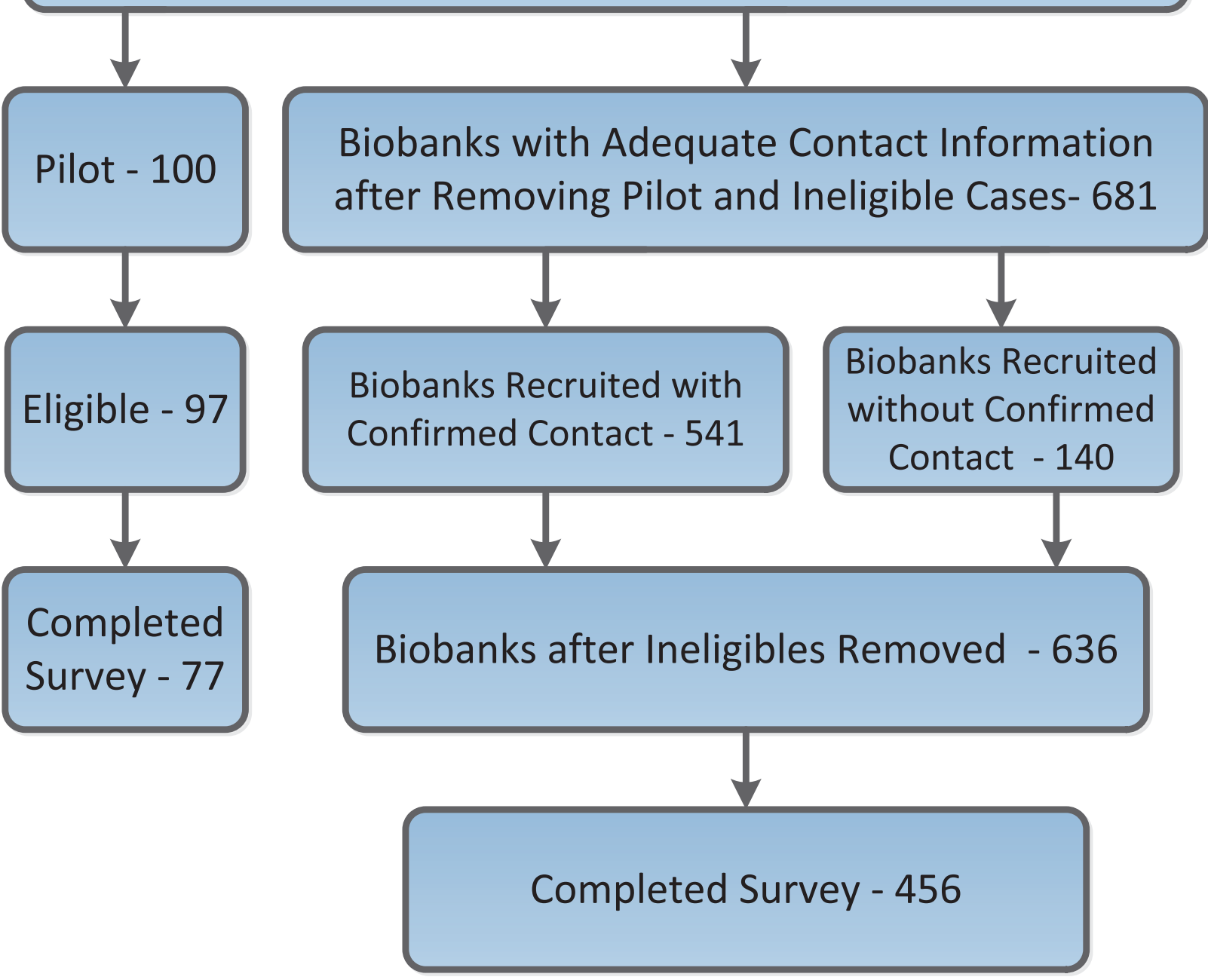

Figure 1 Number of biobank names initially identified, and process of determining eligibility for survey recruitment.

produced a list for survey recruitment. By eliminating duplicates, we reduced our initial 1,741 names of possible biobanks to 894 . We then endeavored to identify the name and current email and postal mail addresses for the director, manager, or other representative from each biobank whom we would eventually recruit to take the survey. We contacted, through email or telephone, these representatives to confirm they had the appropriate knowledge about the biobank to take our survey. In many cases they did, but in some instances the person we contacted nominated someone else in the organization. We attempted to confirm the contact information 
of the nominated individual. During this process, we discovered entities that did not fit our definition of a biobank, were no longer in existence, or whose collections had been transferred to another biobank; we marked these cases as ineligible. Finally, there were some biobanks for which we were never able to discern adequate contact information (either an email address or telephone number), so we were forced to drop them from our list of 894. Ultimately, we identified biobanks in 43 states plus the District of Columbia.

\section{Survey development and pilot}

Questions for the survey were based on results of our six case studies, prior research studies (including surveys of other types of organizations), and the organizational sociology literature. We partnered with the UNC Odum Institute for Research in Social Science for methodological guidance on questionnaire design and on all aspects of survey data collection. Given the measurement challenges we faced, we devoted a six-month period in 2011 to pilot testing all aspects of our survey plan.

For the pilot, we chose a purposive (non-random) sample of 100 biobanks from our list, ensuring that there was representation of the four types of URL extensions in our list (.com, .edu, .gov, and .net, or .org). We first notified biobanks about the upcoming survey via a FedEx letter explaining the study and the incentive for completion (a $\$ 30$ Amazon gift card). As described above, prior to sending the letters, we emailed all biobanks selected for the pilot and asked them to confirm that we had the correct name and contact information for a representative with the knowledge to complete the survey. When necessary, we followed up with phone calls to verify these details. Using such thorough procedures, we were confident we were contacting the correct individual and were able to customize the recruitment letters with the recipient's name. Our goal was to get the potential respondent's attention in a professional way that motivated them to watch for the survey invitation in their email inbox and to complete the survey promptly.

Approximately four days after the FedEx letters were delivered, we emailed invitations to the identified respondent at each biobank. The email contained a hyperlink which took the respondent directly to the survey. Of the 100 individuals we contacted, three replied that their organization did not meet our definition of a biobank and were therefore ineligible. Of the remaining 97 biobanks, 77 completed the survey, for a response rate of $79 \%$. Results of the pilot study were used to revise and improve the survey instrument in preparation for our main survey.

\section{Survey of U.S. biobanks}

Though we modified the survey questionnaire in response to our pilot data, we changed little else in our procedures for the main study. Excluding the 100 biobanks recruited for the pilot survey, our list included 681 biobanks (Figure 1). Of these, we had confirmed contact information for 541; as in the pilot study, these biobanks were recruited by letter sent via FedEx or USPS Express. We did not receive responses to our email and telephone requests to confirm their existence or contact information from 140 biobanks in our list. Without a confirmed contact person or postal address, these biobanks were recruited via email using the email address we had found in our search. In February 2012, a few days after sending the recruitment letters and emails, we emailed survey invitations to these 681 banks. We used email reminders and phone calls to prompt nonrespondents. In the process of data collection, we discovered that an additional 45 biobanks (35 from the 'confirmed contact' group and 10 from the 'unconfirmed contact' group) were ineligible, thus producing a total of 636 eligible biobanks in our study. Upon conclusion of data collection in May 2012, we had 456 completed surveys, representing a response rate of $72 \%$.

\section{Differential response rates and nonresponse bias}

As might be expected, we achieved a significantly higher response rate among the biobanks with previously confirmed contact information than those without $(81 \%$ versus $34 \%, P<0.001)$. However, only $20 \%$ of biobanks (130 of 636) fell into the latter category, so our overall response rate remained high. Assessing risk of nonresponse bias requires observations on both responding and nonresponding units [40]. The only additional, potentially relevant information we have on nonresponding biobanks is the domain portion of their website URL (.com, .edu, .gov, and .net, or .org). We examined response rates by domain and found no statistically significant differences.

Table 1 shows the composition of the responding biobanks compared to the entire list. The responding

\section{Table 1 Comparison of responding biobanks to master} list

\begin{tabular}{lrrrr}
\hline & \multicolumn{2}{c}{ Responding biobanks } & \multicolumn{2}{c}{ Master list } \\
& $\mathbf{n}$ & $\%$ & $\mathbf{n}$ & $\%$ \\
\hline $\begin{array}{l}\text { Contact information confirmed prior to survey } \\
\text { Yes }\end{array}$ & 413 & 91 & 507 & 80 \\
No & 43 & 9 & 130 & 20 \\
$\quad$ Total & 456 & 100 & 637 & 100 \\
Domain portion of URL & & & & \\
.com & 26 & 6 & 40 & 6 \\
.edu & 296 & 65 & 399 & 63 \\
.gov & 26 & 6 & 32 & 5 \\
.org or.net & 108 & 24 & 165 & 26 \\
Total & 456 & 100 & 637 & 100 \\
\hline
\end{tabular}


biobanks closely correspond to the distribution among the four URL domain types.

\section{Coding and analysis methods}

Two types of open-ended questions were used in the survey. The first were stand-alone questions such as 'What is your title or role at [BIOBANK]?' The second were open-ended questions embedded in fixed-response questions, and were typically designed to allow respondents to offer information beyond the fixed responses. For example, we asked, 'What is the main biomolecule [BIOBANK] isolates from specimens, if any?' Fixed responses included 'DNA,' 'RNA,' 'Protein,' 'Other,' and 'None.' Respondents who chose 'Other' were given an openended text box to specify other biomolecules. A codebook was developed for each open-ended question by at least three of the authors (AGN, GEH, and RJC). All open-ended responses were coded in a systematic manner by a primary coder (AGN). Two secondary coders (GEH and RJC) reviewed all codes proposed by the primary coder. When the secondary coders did not agree with the primary coder's choice of codes, the three coders met and resolved inconsistencies through consensus.

Survey data were collected using Illume software version 4.7 (Datstat, Inc., Seattle, WA, USA). Data were analyzed in SAS version 9.2 (SAS Institute Inc., Cary, NC, USA). We present simple response frequencies and cross-tabulations, with percentages where appropriate. Where percentages do not add to 100, it is due to rounding. Most variables are discrete; thus we used chi-square for tests of statistical significance except when small cell sizes dictated use of Fischer's Exact Test.

\section{Results and discussion}

\section{Origins of U.S. biobanks}

Table 2 shows the reported dates of establishment for biobanks in our survey. Though over half (59\%) were established since 2001, 17\% have been in existence for more than 20 years, with seven banks over 50 years old.

Respondents were asked to 'check all that apply' in a list of reasons that their biobank might have been established, and then asked to report the most important reason. Table 3 shows that over half of the banks (53\%) were established primarily to facilitate research on a particular

Table 2 Year of establishment

\begin{tabular}{lll}
\hline & $\mathbf{n}$ & $\%$ \\
\hline 1980 or earlier & 30 & 7 \\
1981 to 1990 & 46 & 10 \\
1991 to 2000 & 109 & 24 \\
2001 to 2010 & 249 & 56 \\
2011 or later & 13 & 3 \\
Total & 447 & 100 \\
\hline
\end{tabular}

disease or type of disease. Though we did not ask what specific disease prompted establishment, it is clear from reading responses to this and other open-ended survey questions that by far the largest portion focus on cancer, followed by neurological diseases (such as Alzheimer's), and HIV/AIDS. The second most frequent primary reason for establishment was to facilitate research generally (29\%). The remaining $19 \%$ of biobanks were primarily developed for various unique reasons specific to their circumstances, such as in response to a grant, to organize or consolidate existing collections, or to store specimens for others.

As shown in Table 3, we examined whether biobanks established prior to the sequencing of the human genome in 2003 were more likely to have been established to facilitate research on a particular disease compared to those established after 2003 (59\% versus 45\%). After 2003, although studying a particular disease was still the most common reason for establishment, significantly more biobanks were created to facilitate research generally, compared to years prior to 2003 (38\% versus $22 \%, P<0.01$ ). While there are likely multiple explanations for these results, it is possible that the changing landscape of genomic technology has facilitated a broadening of scope in research pursuits so that biobanks are not as likely to limit their work to one disease.

\section{Specimen collections}

The number of specimens currently in storage by the responding biobanks ranged from tens to over 50 million. The distribution is shown in Table 4. Due to a small number of very large banks, the mean number of specimens reported was 461,396 ; the median was 8000 . As can be seen from Table 4, it is difficult to discern a 'typical' sized collection; rather, biobank collections in the U.S. cover a wide spectrum of very small to very large. It should be noted that the survey question asked how many specimens the bank currently stored, which may not be the best measure of size for some banks. Some respondents provided comments at the end of the survey indicating that the number of specimens they have in storage at any given time varies greatly.

The number of specimens in storage can reflect duplicate contributions and processed derivatives of contributed samples, so we also asked respondents approximately how many individual contributors were represented among their specimens in storage. Responses ranged from just a few to 10 million. To get an idea of the number of contributors typically represented in biobanks relative to the number of specimens, we calculated the ratio of specimens to contributors for each biobank. The values ranged from 1 (one specimen per contributor) to 277. The mean number was 12.6; however the distribution was skewed by a small number of banks with large numbers of specimens 
Table 3 Primary reason for establishment by date

\begin{tabular}{|c|c|c|c|c|c|c|c|c|}
\hline \multirow[t]{2}{*}{ Year established } & \multicolumn{2}{|c|}{ Facilitate research on a particular disease or type of disease } & \multicolumn{2}{|c|}{ Facilitate research generally } & \multicolumn{2}{|c|}{ Other reason } & \multicolumn{2}{|c|}{ Total } \\
\hline & $\mathbf{n}$ & $\%$ & $\mathbf{n}$ & $\%$ & n & $\%$ & $\mathbf{n}$ & $\%$ \\
\hline Before 2003 & 137 & 59 & 50 & 22 & 45 & 19 & 232 & 54 \\
\hline 2003 or later & 87 & 45 & 73 & 38 & 34 & 18 & 194 & 46 \\
\hline Total & 224 & 53 & 123 & 29 & 79 & 19 & 426 & 100 \\
\hline
\end{tabular}

$\mathrm{X}^{2}=13.71, P<0.01$

per contributor. Thus, the modal response was 1 and the median was 3.2 even though the mean was 12.6. Most biobanks (65\%) had a ratio of 5 or fewer specimens to contributors. Thus, it appears that most biobanks contain only a small number of specimens from each contributor.

We asked respondents which type(s) of biological specimen(s) their bank stores. As shown in Table 5, serum or plasma are the specimens most commonly stored (77\% of biobanks have them) with solid tissues following close behind (69\%). Fifty-five percent of biobanks store whole blood, and $49 \%$ store peripheral blood cells or bone marrow. Though cord blood or cord derivatives were the least common among the categories we specifically asked about (11\%), by coding the 'other, please specify' responses, we determined that $7 \%$ of biobanks store pathological body fluids (such as the peritoneal fluid that accumulates in ascites) and 3\% store hair or toenails - two categories we had not anticipated to be this common.

As shown in Table 6, most biobanks (87\%) store more than one type of specimen; $8 \%$ store eight or more types. The most frequent combination of types was whole blood, plasma, and solid tissues. Banks with only one type of specimen are most likely to be those which only store solid tissue.

We asked respondents to identify the main biomolecule their bank isolates from specimens, if any. Nearly $50 \%$ said 'DNA,' $11 \%$ said 'RNA,' and 7\% said 'Protein.' Twenty-four percent of respondents indicated 'None.' The 9\% who chose 'Other' provided open-ended

Table 4 Number of specimens in storage

\begin{tabular}{lll}
\hline & $\mathbf{n}$ & $\%$ \\
\hline Less than 500 & 63 & 15 \\
500 to 999 & 28 & 7 \\
1000 to 1999 & 31 & 7 \\
2000 to 4999 & 54 & 13 \\
5000 to 9999 & 44 & 10 \\
10,000 to 49,999 & 70 & 16 \\
50,000 to 99,999 & 38 & 9 \\
100,000 to 499,999 & 65 & 15 \\
$500,000+$ & 33 & 8 \\
Total & 426 & 100 \\
\hline
\end{tabular}

Mean: 461,396; standard deviation: 3,324,096; median: 8000; interquartile range: 1,200 to 76,000; skewness: 12.76; kurtosis: 181. responses to explain. Virtually all indicated that they were unable to choose just one biomolecule because the biobank isolates more than one in equal proportions (most frequently DNA and others). The large percentage of respondents who indicated their banks were isolating DNA (and RNA) suggests that the majority of biobanks are engaging in genetic research of one sort or another.

We wanted to determine biobanks' sources for acquiring specimens. As shown in Table 7, the two largest sources of specimens are direct contribution by individuals (75\%) and residual specimens from hospitals and other clinical settings (57\%). In fact, many (41\%) include specimens from both these sources, and only $8 \%$ do not report either individuals or clinical settings as sources of specimens. The third largest source of specimens is research studies (13\%). Other sources reported by a small number of biobanks include vendors, organ or body donation organizations, other repositories, or that they acquired 'orphaned' collections (those which were presumably abandoned by their original owners).

Respondents were asked whether specimens in their collection represent any particular group(s) of individuals. Forty-four percent of biobanks store specimens from children under the age of 18 , though only $2 \%$ house exclusively pediatric specimens. In $36 \%$ of biobanks, the collection includes specimens collected postmortem, including $9 \%$ which store exclusively postmortem specimens, most of which are brain banks.

\section{Table 5 Types of specimens in storage (check all that} apply)

\begin{tabular}{lll}
\hline Percentage of biobanks storing specimens of this type & $\mathbf{n}$ & \% \\
\hline Serum or plasma & 349 & 77 \\
Solid tissue specimens, including paraffin-embedded, frozen, & 315 & 69 \\
or other & & \\
Whole blood & 251 & 55 \\
Peripheral blood cells or bone marrow & 222 & 49 \\
Cell lines & 162 & 36 \\
Saliva or buccal cells & 155 & 34 \\
Urine or stool & 138 & 30 \\
Cerebral spinal fluid & 85 & 19 \\
Cord blood or cord blood derivatives & 51 & 11 \\
Other biological specimens & 40 & 9 \\
Pathological body fluids & 30 & 7 \\
Hair/toenails & 14 & 3 \\
\hline
\end{tabular}


Table 6 Number of types of specimens in storage

\begin{tabular}{lll}
\hline & $\mathbf{n}$ & $\%$ \\
\hline 1 & 58 & 13 \\
2 & 59 & 13 \\
3 & 81 & 18 \\
4 & 62 & 14 \\
5 & 66 & 15 \\
6 & 50 & 11 \\
7 & 38 & 8 \\
$8+$ & 36 & 8 \\
Total & 453 & 100 \\
\hline
\end{tabular}

As shown in Table 8, 76\% of respondents indicated their biobank's specimens come primarily from individuals with a particular disease or type of disease, and an equal proportion reported that their specimens come primarily from patients in a specific hospital or clinic. Over half (60\%) endorsed both 'individuals with a particular disease or type of disease' and 'patients from specific hospital(s) or clinic(s).' It is not clear from our data whether this represents two descriptors of the same group (patients in particular clinical settings who have a particular disease) or whether these biobanks have different sub-collections, though we believe the former explanation is most logical. Similarly, 34\% of respondents reported both that their biobank's specimens are primarily drawn from clinical trials patients and from specific hospital or clinical settings. An equal fraction (34\%) endorsed both 'participants in clinical trials' and 'patients with a particular disease or type of disease.'

\section{Organizational characteristics}

Only 5\% of responding biobanks are for-profit organizations. Seven percent are incorporated. Regardless of organizational form, $80 \%$ have internal oversight boards of some kind. We asked whether each biobank is 'part of a network of biobanks.' Sixteen percent indicated they were and then filled in the name of the network. Based on detailed review of these open-ended responses, it is clear that respondents interpreted 'network' broadly.
Responses included programs, registries, cooperative groups, multi-site studies, and consortia that were NIH sponsored, state-sponsored and population based, intraand inter-institutional, and national and international. A few banks listed more than one network.

Most biobanks are affiliated in one or multiple ways with other organizations. Determining the presence and nature of biobanks' affiliations or locations within larger organizations proved very difficult - so difficult, in fact, that it took us three attempts to develop a suitable question. Following the pilot study, we rewrote the survey questions about being part of a larger organization. Despite our best efforts, it became clear midway through our data collection effort that we still had not asked the questions in a way respondents understood as we intended. For example, we found biobanks that were clearly part of universities whose respondents identified the bank as an 'independent organization.' For this reason, we clarified the wording of our survey question (adding 'such as a university, a hospital, government, a research institute, or any other type of larger organization' to our original question wording of 'Is your biobank an independent organization or part of some larger organization?'). We re-contacted the 121 biobanks who had responded that they were 'independent' prior to this modification in order to ensure they were properly classified. Through these efforts, we determined that $88 \%$ of responding biobanks were part of larger organizations and only $12 \%$ were independent in the ways we intended to use the terms.

Further characterizations of biobanks within larger entities were equally challenging. When biobanks were part of larger organizations, we asked respondents to indicate the nature of the larger organization(s), using a provided list of eight organizational types and space to write in others. Among biobanks that are part of one or more larger organizations (which we call 'embedded'), Table 9 shows the percentage that checked each type of organization. Clearly the most frequent affiliation of a biobank is within an academic institution (78\% of embedded banks). Hospitals were reported as a parent organization for $27 \%$, and $15 \%$ were part of a research

Table 7 Acquisition of specimens (check all that apply)

\begin{tabular}{|c|c|c|}
\hline Percentage of biobanks which get specimens from... & n & $\%$ \\
\hline Direct from individuals donating them & 343 & 75 \\
\hline Residual specimens acquired from clinical care in hospitals, clinical laboratories, or pathology departments & 261 & 57 \\
\hline Research & 60 & 13 \\
\hline Residual specimens from public health departments or programs & 19 & 4 \\
\hline Vendors & 8 & 2 \\
\hline Organ/body donation organization & 7 & 2 \\
\hline Other repositories & 7 & 2 \\
\hline Other & 6 & 1 \\
\hline Orphaned collections & 4 & 1 \\
\hline
\end{tabular}


Table 8 Specimen contributors (check all that apply)

\begin{tabular}{lll}
\hline Percentage of biobanks reporting that their specimens are drawn primarily from... & $\mathbf{n}$ & $\%$ \\
\hline Individuals with a particular disease or type of disease & 335 & 76 \\
Patients from specific hospital(s) or clinic(s) & 331 & 76 \\
Participants in a cohort study & 184 & 40 \\
Participants in clinical trials & 180 & 39 \\
Individuals from a specific geographic area (including community-based biobank) & 122 & 27 \\
\hline
\end{tabular}

institute. About a quarter (28\%) of all biobanks are part of more than one larger organization. Table 10 provides details. By far the most common situation of multiple affiliation is for a biobank to be affiliated with an academic institution and also with another organization - a hospital being a second affiliation for more than half (73\%) of academic biobanks with multiple affiliations. The next most common multiple affiliation is within an academic institution and also a research institute (34\% of biobanks affiliated with academic institutions are also part of a research institute).

Very few non-academic biobanks are embedded within more than a single larger organization. Most are solely within a single larger entity, and it is most likely to be the federal government (29\%), or a hospital or research institute (18\% each).

For many biobanks, being embedded within a larger organization is critical to its financial structure. Together with the federal government, the larger organizations named by biobanks are the most common and largest sources of funding. Tables 11 and 12 show the results of our questions regarding the bank's largest source of current funding (Table 11) and funding provided within the past 5 years (or since establishment for biobanks younger than 5 years) by a list of possible sources (Table 12). The federal government is the largest funding source for $36 \%$ of biobanks and provided some amount of funding in the past 5 years to $57 \%$ of responding biobanks. The larger

Table 9 Type of larger organizations biobank is part of (check all that apply)

\begin{tabular}{lll}
\hline & $\mathbf{n}$ & $\%$ \\
\hline Academic institution & 307 & 78 \\
Hospital or health care organization & 105 & 27 \\
Research institute & 60 & 15 \\
Federal government & 38 & 10 \\
Disease or health advocacy organization & 19 & 5 \\
State government & 17 & 4 \\
Philanthropic organization & 11 & 3 \\
Corporation & 10 & 3 \\
Other & 7 & 2 \\
Consortium & 5 & 1 \\
\hline
\end{tabular}

Note: Table includes only biobanks which are embedded in at least one larger organization $(n=394)$ organization is the largest current source for $30 \%$ of biobanks and provided some amount of funding for $59 \%$ of biobanks within the past 5 years. Fees for services (primary for $11 \%$ and within-5-year source for $44 \%$ ) and funding from individuals or foundations (primary for $10 \%$ and within-5-year source for $40 \%$ ) were also common. In a separate question, we asked biobanks that are not part of government agencies but nonetheless receive government funding to indicate the extent to which they are dependent on government funding to maintain operation. Among these, $34 \%$ are completely dependent, $36 \%$ are mostly dependent, $22 \%$ are somewhat dependent, and only $8 \%$ are not at all dependent on government funding.

Taken together, these data on embeddedness and multiple affiliations demonstrate the inadequacy of simple classifications of biobanks as 'government, academia, or industry.' For example, the approximately 300 biobanks that identify themselves as 'academic' have essentially the same degree of diversity in organizational features (such as size of collection and sources of acquisition) as the full set of responding biobanks (data not shown).

\section{Market context and sustainability}

To learn about the 'market' in which biobanks operate, we asked respondents whether their biobank is in competition with other biobanks to provide specimens and data to researchers. Only $14 \%$ said yes. Of these 57 biobanks, only 4 said there is 'a great deal' of competition; 29 (51\%) said there is a moderate amount of competition, and 24 $(42 \%)$ said there is very little competition. Overall, then,

Table 10 Number of types of organizations biobank is part of, by academic affiliation

\begin{tabular}{lllll}
\hline & $\begin{array}{l}\text { With academic } \\
\text { affiliation } \\
\end{array}$ & $\mathbf{n}$ & $\%$ & $\begin{array}{l}\text { Without academic } \\
\text { affiliation }\end{array}$ \\
\hline 0 (independent) & 0 & 0 & $\mathbf{n}$ & $\%$ \\
1 & 189 & 62 & 54 & 38 \\
2 & 71 & 23 & 10 & 55 \\
3 & 38 & 12 & 0 & 7 \\
4 & 5 & 2 & 0 & 0 \\
5 & 3 & 1 & 0 & 0 \\
6 & 1 & 0 & 0 & 0 \\
Total & 307 & 100 & 141 & 0 \\
\hline
\end{tabular}


Table 11 Largest current source of funding

\begin{tabular}{lll}
\hline & $\mathbf{n}$ & $\%$ \\
\hline Federal government & 158 & 36 \\
The larger organization biobank is a part of & 133 & 30 \\
Fees for services & 49 & 11 \\
Individuals or foundations & 43 & 10 \\
State government & 11 & 2 \\
Clinical and Translational Science Award & 11 & 2 \\
Sale of specimens & 10 & 2 \\
Other & 10 & 2 \\
Sale of other products & 9 & 2 \\
The network to which biobank belongs & 5 & 1 \\
None & 4 & 1 \\
Total & 443 & 100 \\
\hline
\end{tabular}

only $33(8 \%)$ of responding biobanks reported that they experience a great deal or a moderate amount of competition. For-profit biobanks are significantly more likely to report being in competition than others (61\% versus $12 \%$, $P<0.001)$. It would appear that most biobanks fill a particular 'niche' within their larger organization or research area and generally do not seem concerned about losing their 'market.' This sentiment is echoed in responses to questions about demand for biobank products and services, where $51 \%$ of respondents report that demand for their bank's services has increased in the past 2 years. Only $6 \%$ said demand decreased, and $43 \%$ said it stayed about the same.

While concerns about competition and demand were not substantial, many respondents did express concern about sustainability, typically linked with financial needs. Forty-one percent consider this a major concern, 31\% a moderate concern, and $20 \%$ a minor concern; only $9 \%$ report it is not at all a concern. As might be expected, running out of funding is significantly less likely to be a

Table 12 Funding sources in past 5 years (check all that apply)

\begin{tabular}{lll}
\hline $\begin{array}{l}\text { Percentage of biobanks which received any funding } \\
\text { from... }\end{array}$ & $\mathbf{n}$ & $\%$ \\
\hline The larger organization biobank is part of & 269 & 59 \\
Federal government & 260 & 57 \\
Fees for services & 200 & 44 \\
Individuals or foundations & 182 & 40 \\
Sale of specimens & 68 & 15 \\
State government & 53 & 12 \\
Clinical and Translational Science Award & 47 & 10 \\
The network to which biobank belongs & 33 & 7 \\
Sale of other products & 30 & 7 \\
Interest or dividends & 15 & 3 \\
Licensing technologies & 14 & 3 \\
Local government & 5 & 1 \\
\hline
\end{tabular}

major or moderate concern for biobanks which rely on sales (of specimens or other products) and fees for services as their primary funding source than it is for others $(58 \%$ versus $74 \%, P<0.01)$. A final marketplace concern for some biobanks is the underutilization of their specimen collections. Thirteen percent report that this is a major concern, $28 \%$ say it is a moderate concern, for another $28 \%$ it is a minor concern, and $31 \%$ said it is not at all a concern.

\section{Conclusions}

In this paper we describe both the process by which we conducted a national U.S. biobank survey and results from that survey. As the first survey of its kind in the U. S., our study has inevitable limitations, particularly in attempting to characterize such a diverse universe of organizations. Given the lack of a comprehensive registry of biobanks from which to sample, our survey cannot claim statistical inference to all U.S. biobanks. However, our systematic, multi-faceted searches for online presence produced a reasonable approximation of all biobanks in existence in the U.S. at this time. We achieved a high survey response rate, but we cannot speak to whether our results would have been different had the other $28 \%$ of banks responded. The only significant bias in survey response was whether we had established contact with a potential respondent; this was not, however, related to the biobank's URL domain. (The various URL domains were represented in appropriate proportions among our responding biobanks.) Finally, we document that over half of our respondent banks were established since 2001. While we believe this reflects a burgeoning industry, it does not take into account survival bias. There were undoubtedly some biobanks that were in existence before 2001 but did not survive to be included in our list.

Despite these limitations, the documentation of tremendous diversity in the origins, collections, organizational features, and market contexts of biobanks in the U.S. is important. This diversity raises questions about the utility of the simple classification schemes employed in the past. Our results strongly suggest that a multidimensional classification scheme is needed that will enable nuanced attention to the policies and practices that biobanks employ to carry out their work.

Biobanks are not a new phenomenon. However, the steep rate of increase in establishment in the last decade is a sign of rapid change, and likely also contributes to the organizational diversity we document. Undoubtedly, some of this increase may be attributed to advances in genomics and bioinformatics and increased emphasis on translational research, all of which stimulate the demand for stored specimens and associated data. In fact, our survey results indicate that the majority of biobanks are 
storing specimens that can be used for genetic or genomic research, which raises particular concerns regarding privacy and identifiability [41]. Our prior work on genetic researchers' perspectives documents their reluctance to discard samples [42], and preliminary data analysis from our case studies and open-ended comments from our survey confirm this belief in the tremendous value of research specimens.

Findings that document highly diverse numbers, types, and sources of specimen collections raise questions regarding how biobanks should be managed and governed. For example, while the large number of banks that collect and retain residual clinical specimens is unsurprising, it is nevertheless important because of recent controversies regarding whether and how consent for such specimens should be obtained [41,43-45]. Perhaps more surprising is our finding that such a large number of biobanks contain pediatric and postmortem specimens in their collections, along with specimens from other sources. While biobanks with exclusively pediatric or postmortem specimens ( $9 \%$ and $2 \%$ of our surveyed biobanks, respectively) typically adopt particular guidelines for human subjects protections, it is less clear how these specimens might impact governance in mixed-source collections.

Most biobanks are embedded in one or more other entities. The fact that over one-quarter of surveyed biobanks are part of more than one larger organization creates significant classification problems. Embeddedness makes it harder to understand how policies and practices are enacted, as it may be unclear where the locus of decision-making resides. More research is needed to understand the complexity of biobanks' relationships with other organizations and how these relationships impact their work.

The finding of remarkable diversity in organizational characteristics is typical of an emerging industry in the early and rapidly evolving stages of development [46]. In fact, a striking finding of rapid turnover in this industry was actually a by-product of our work to create the biobank list (for which the majority of biobanks classified as ineligible after correspondence with each biobank's potential respondent was due to the bank no longer being in operation). Organizational theory would predict that new, innovative forms of biobanks will arise and survive based on a variety of both internal and external factors [46], that these factors may be studied to understand organizations' survival strategies $[47,48]$, and that some forms will become institutionalized over time $[49,50]$.

Capturing the full range of organizational configurations will be important moving forward as the market for biobank services is likely to increase in complexity, and possibly in the mixture of interrelated forms such as public-private partnerships, vertical and horizontal networks, and other types of out-sourcing or combined practices. It is difficult to predict the nature and extent of change for biobank organizations. However, given that the majority of respondents in our study expressed concern about funding and underutilization, one scenario is that biobanks will coalesce around a limited number of organizational forms in order to maximize survival, and that those with similar missions may join together to form larger collections, or join networks or consortia to endeavor to stabilize funding and increase utilization. Regulatory agencies, professional associations, or influence exerted by more established biobanks on latecomers might all promote convergence of organizational types. Conversely, a different scenario would predict that biobanks are driven toward increased diversity by rapid changes in technology, customization, and the need to differentiate to address more particularized markets. Innovation might be found more in independent biobank markets where fewer forces may exist to compel banks to be more similar [49]. These are important topics for future research, especially as they relate to utilization of biobank resources and ensuring that biobanks meet their promise as effective vehicles for translational research.

As part of the research enterprise, biobanks, like the researchers who depend on their services and specimens, need guidance informed by knowledge of their practices and challenges. The complex organizational landscape of biobanking requires policies as nuanced as the biobanks themselves, whether those policies address subject protection or privacy, or the advancement of research goals. Given different stakeholders and missions, it is unlikely that one-size policies will fit all biobanks, but attention to organizational diversity is critical for the promotion of appropriate and effective biobank governance.

\section{Abbreviations}

CTSA: Clinical and Translational Science Award; NIH: National Institutes of Health; RAND: Research ANd Development Corporation; UNC: University of North Carolina at Chapel Hill.

\section{Authors' contributions}

RJC, GEH, CZ, TE, IC, BJW, JPE, and AMD conceived of the study and its design. RJC, AGN, IC, GEH, and TE were involved in acquisition of data. RJC, GEH, AGN, JPE, CZ, IC, BW, and TE were involved in data analysis. All authors participated in drafting the manuscript. All authors read and approved the final manuscript.

\section{Authors' information}

Our authors include individuals with expertise in genetics, medicine, and biobank management (JPE), organizational studies (BJW, CRZ), survey research methodology $(T E, I C, R J C)$, law (AMD), and social science studies of ethical, legal, and social aspects of genetics and genomics (GEH, RJC, AMD).

\section{Competing interests}

The authors declare that they have no competing interests. 


\section{Acknowledgements}

We wish to thank the people who graciously participated in our survey. Rene Sterling was central to the original conceptualization of the biobank study. The following people helped building the biobank list: Kelle Basta, Greg Boyer, Mark Cornell, Maria Hobbs, Kriste Kuczynski, Jennifer Lewis, Marsha Michie, Erik Reavely, and Warren Whipple. Sally Morris and Matthew Minnotte helped with the survey administration. Funding for this project was provided by grant numbers 1R01HG005227-01A1 (GEH, principal investigator, 'From Specimen to Biobank: Using An Organizational. Perspective To Study ELSI Issues') from the National Human Genome Research Institute, and 5UL1RR025747-04S1, a supplement to the UNC CTSA U54RR024382-01A1 (Runge, M., principal investigator, 'Enhancing Biobank Capacities Across (TSAs'). Support was also provided by the UNC Center for Genomics and Society, P50 HG004488 from the National Human Genome Research Institute. The content of this article does not necessarily reflect the views or policies of the funding agencies.

\section{Author details}

${ }^{1}$ Department of Social Medicine, CB 7240, University of North Carolina at Chapel Hill, Chapel Hill, NC 27599-7240, USA. ${ }^{2}$ HW Odum Institute for Research in Social Science, University of North Carolina at Chapel Hill, Chapel Hill, NC 27599-3355, USA. ${ }^{3}$ Department of Sociology, University of North Carolina at Chapel Hill, Chapel Hill, NC 27599-3355, USA. ${ }^{4}$ Department of Genetics, CB 7264, University of North Carolina at Chapel Hill, Chapel Hill, NC 27599-7264, USA. ${ }^{5}$ Department of Health Policy and Management, CB 7411, UNC Gillings School of Global Public Health, University of North Carolina at Chapel Hill, Chapel Hill, NC 27599-7411, USA.

Received: 20 November 2012 Revised: 17 December 2012

Accepted: 25 January 2013 Published: 25 January 2013

\section{References}

1. Hoeyer K: Size matters: the ethical, legal, and social issues surrounding large-scale genetic biobank initiatives. Norsk Epidemiologi 2012, 21:211-220.

2. Capron A, Mauron A, Elger B: Ethical norms and the international governance of genetic databases and biobanks: findings from an international study. Kennedy Inst Ethics J 2009, 19:101-124.

3. Clayton EW, McGuire AL: The legal risks of returning results of genomics research. Genet Med 2012, 14:473-7.

4. Fullerton SM, Wolf WA, Brothers KB, Clayton EW, Crawford DC, Denny JC, Greenland P, Koenig BA, Leppig KA, Lindor NM, McCarty CA, McGuire AL, McPeek Hinz ER, Mirel DB, Ramos EM, Ritchie MD, Smith ME, Waudby CJ, Burke W, Jarvik GP: Return of individual research results from genomewide association studies: experience of the Electronic Medical Records and Genomics (eMERGE) Network. Genet Med 2012, 14:424-431.

5. Gibbons SMC: Regulating biobanks: a twelve-point typological tool. Med Law Rev 2009, 17:313-346.

6. Knoppers BM, Isasi R: Stem cell banking: between traceability and identifiability. Genome Med 2010, 2:73.

7. McGuire A, Beskow L: Informed consent in genomics and genetic research. Annu Rev Genomics Hum Genet 2010, 11:361-381.

8. O'Doherty KC, Burgess MM, Edwards K, Gallagher RP, Hawkins AK, Kaye J, McCaffrey $V$, Winickoff DE: From consent to institutions: designing adaptive governance for genomic biobanks. Soc Sci Med 2011, 73:367-374.

9. Wolf SM, Crock BN, Ness BV, Lawrenz F, Kahn JP, Beskow LM, Cho MK, Christman MF, Green RC, Hall R, Illes J, Keane M, Knoppers BM, Koenig BA, Kohane IS, LeRoy B, Maschke KJ, McGeveran W, Ossorio P, Parker LS, Petersen GM, Richardson HS, Scott JA, Terry SF, Wilfond BS, Wolf WA: Managing incidental findings and research results in genomic research involving biobanks and archived data sets. Genet Med 2012, 14:361-384.

10. International Human Genome Sequencing Consortium: Finishing the euchromatic sequence of the human genome. Nature 2004, 431:931-945.

11. Caulfield T, Knoppers B: Consent, Privacy \& Research Biobanks: Policy Brief No. 1 Genomics, public policy and society. Genome Canada; 2010, 1-10, Available from http://www.genomecanada.ca/medias/pdf/en/GPS-PolicyDirections-Brief.pdf

12. Green ED, Guyer MS: Charting a course for genomic medicine from base pairs to bedside. Nature 2011, 470:204-213.

13. Eiseman E, Haga S: Handbook of Human Tissue Sources: A National Resource of Human Tissue Samples Santa Monica: RAND; 1999.
14. National Bioethics Advisory Commission: Research Involving Human Biological Materials: Ethical Issues and Policy Guidance Rockville, MD: NBAC; 1999.

15. Eiseman E, Bloom G, Brower J, Clancy N, Olmstead S: Case Studies of Existing Human Tissue Repositories Santa Monica: RAND; 2003.

16. Watson PH, Barnes RO: A proposed schema for classifying human research biobanks. Biopreservation and Biobanking 2011, 9:327-333.

17. Cambon-Thomsen A: The social and ethical issues of post-genomic human biobanks. Nature Rev Genet 2004, 5:866-873.

18. Hirtzlin I, Dubreuil C, Préaubert N, Duchier J, Jansen B, Simon J, Lobato De Faria P, Perez-Lezaun A, Visser B, Williams GD, Cambon-Thomsen A: An empirical survey on biobanking of human genetic material and data in six EU countries. Eur J Human Genet 2003, 11:475-488.

19. Hoeyer K: The power of ethics: a case study from Sweden on the social life of moral concerns in policy processes. Sociol Health IIIn 2006, 28:785-801.

20. Kaye J: Do we need a uniform regulatory system for biobanks across Europe?. Eur J Human Genet 2006, 14:245-248.

21. Kaye J, Gibbons SMC, Henney C, Al E: Governing Biobanks: Understanding the Interplay Between Law and Practice Oxford and Portland Oregon: Hart Publishing; 2012.

22. Pálsson G: Anthropology and the New Genetics. 1 edition. Cambridge: Cambridge University Press; 2007, 280

23. Shickle D, Griffin M, El-Arifi K: Inter- and intra-biobank networks: classification of biobanks. Pathobiology 2010, 77:181-190.

24. Stranger M, Bell E, Nicol D, Otlowski M, Chalmers D: Human genetic databanks in Australia: indications of inconsistency and confusion. New Genetics and Society 2008, 27:311-321.

25. In Genetic Databases: Socio-Ethical Issues in the Collection and use of DNA. Edited by: Tutton R, Corrigan O. New York: Taylor 2004:.

26. Beskow $L M$, Burke $W$ : Offering individual genetic research results: context matters. Sci Trans/ Med 2010, 2:38cm20.

27. Bledsoe MJ, Grizzle WE, Clark BJ, Zeps N: Practical implementation issues and challenges for biobanks in the return of individual research results. Genet Med 2012, 14:478-483.

28. Johnson $G$, Lawrenz $F$, Thao M: An empirical examination of the management of return of individual research results and incidental findings in genomic biobanks. Genet Med 2012, 14:444-450.

29. Brothers KB, Morrison DR, Clayton EW: Two large-scale surveys on community attitudes toward an opt-out biobank. Am J Med Genet A 2011, 155A:2982-2990

30. Cadigan RJ, Davis AM: Deciding whether to participate in a biobank: the concerns of healthy volunteers. In Principles and Practice in Biobank Governance. Edited by: Kaye J, Stranger M. Burlington, VT: Ashgate Publishing Ltd:; 2009:117-133.

31. Caulfield T, Rachul C, Nelson E: Biobanking, consent, and control: a survey of Albertans on key research ethics issues. Biopreservation and Biobanking 2012, 10:433-438.

32. Dressler LG, Smolek S, Ponsaran R, Markey JM, Starks H, Gerson N, Lewis S, Press N, Juengst E, Wiesner GL: IRB perspectives on the return of individual results from genomic research. Genet Med 2012, 14:215-222.

33. Kaufman D, Murphy-Bollinger J: Public opinion about the importance of privacy in biobank research. Am J Human Genet 2009, 85:643-654.

34. Lemke A, Halverson C, Ross LF: Biobank participation and returning research results: perspectives from a deliberative engagement in South Side Chicago. Am J Med Genet A 2012, 158A:1029-1037.

35. McCarty CA, Garber A, Reeser JC, Fost NC: Study newsletters, community and ethics advisory boards, and focus group discussions provide ongoing feedback for a large biobank. Am J Med Genet A 2011, 155A:737-741.

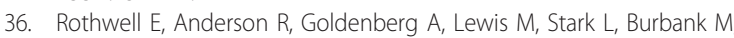
Wong B, Botkin J: Assessing public attitudes on the retention and use of residual newborn screening blood samples: a focus group study. Soc Sci Med 2012, 74:1305-1309.

37. Simon CM, Newbury E, 'heureux JL: Protecting participants, promoting progress: public perspectives on community advisory boards (CABs) in biobanking. J Empir Res Hum Res Ethics 2011, 6:19-30.

38. Streicher S, Sanderson SC, Jabs EW, Diefenbach M, Smirnoff M, Peter I, Horowitz CR, Brenner B, Richardson LD: Reasons for participating and genetic information needs among racially and ethnically diverse biobank participants: a focus group study. J Community Genet 2011, 2:153-163 
39. Boyer GJ, Whipple W, Cadigan RJ, Henderson GE: Biobanks in the United States: how to identify an undefined and rapidly evolving population. Biopreservation and Biobanking 2012, 10:511-517.

40. Groves R, Couper M: Nonresponse in Household Interview Surveys New York: John Wiley \& Sons, Ltd; 1998.

41. Presidential Commission for the Study of Bioethical Issues: Privacy and Progress in Whole Genome Sequencing Washington, DC: Presidential Commission for the Study of Bioethical Issues; 2012.

42. Cadigan RJ, Easter MM, Dobson AW, Davis AM, Rothschild BB, Zimmer C, Sterling R, Henderson G: 'That's a good question': university researchers' views on ownership and retention of human genetic specimens. Genet Med 2011, 13:569-575

43. Emanuel $E J, P h D$, Menikoff J: Reforming the regulations governing research with human subjects. New Engl J Med 2011, 1145-1150.

44. Homer N, Szelinger S, Redman M, Duggan D, Tembe W, Muehling J, Pearson JV, Stephan DA, Nelson SF, Craig DW: Resolving individuals contributing trace amounts of DNA to highly complex mixtures using high-density SNP genotyping microarrays. PLoS Genet 2008, 4:e1000167.

45. Malin B, Loukides G, Benitez K, Clayton EW: Identifiability in biobanks: models, measures, and mitigation strategies. Hum Genet 2011, 130:383-392.

46. Aldrich HE, Ruef M: Organizations Evolving. 2 edition. Thousand Oaks, CA: Sage Publications; 2006.

47. Hannan M, Freeman J: The population ecology of organizations. Am J Sociol 1977, 82:929-964.

48. Pfeffer J, Salancik G: The External Control of Organizations: A Resource Dependence Perspective New York: Harper \& Row; 1978

49. Dimaggio PJ, Powell WW: The Iron Cage revisited: institutional isomorphism and collective rationality in organizational fields. Am Sociol Rev 1983, 48:147-160.

50. Suchman MC: Managing legitimacy: strategic and institutional approaches. Academy of Management Review 1995, 20:571-610.

\section{doi:10.1186/gm407}

Cite this article as: Henderson et al.: Characterizing biobank organizations in the U.S.: results from a national survey. Genome Medicine 2013 5:3.

\section{Submit your next manuscript to BioMed Central and take full advantage of:}

- Convenient online submission

- Thorough peer review

- No space constraints or color figure charges

- Immediate publication on acceptance

- Inclusion in PubMed, CAS, Scopus and Google Scholar

- Research which is freely available for redistribution

Submit your manuscript at www.biomedcentral.com/submit 